\title{
Title: Are nursing students in Hong Kong well- prepared for urinary incontinence care?
}

\author{
CHENG Lai Sheung Winnie \\ Tung Wah College, \\ Hong Kong \\ Email: winniecheng@twc.edu.hk
}

\begin{abstract}
Background: Urinary incontinence is a common disorder that affects men and women of all ages. An effective management of urinary incontinence requires adequate knowledge and positive attitudes from health care professionals. Nursing students who share similar care tasks with qualified nurses should have adequate knowledge to provide quality continence care. There is little evidence to inform the knowledge and attitudes toward urinary incontinence among nursing students in Hong Kong. The purpose of this study was to examine nursing students' urinary incontinence knowledge and attitude. Methods: A crosssectional survey was conducted in February 2017. A sample of 392 nursing students from 5 different educational institutions in Hong Kong was recruited. Two validated questionnaires, the Urinary Incontinence Knowledge Scale (UIKS) and Urinary Incontinence Attitude Scale (UIAS) were used to measure knowledge and attitudes towards urinary incontinence respectively. Results: Overall urinary incontinence knowledge was moderate $(73.3 \%$, mean $22.0 / 30$, SD 4.4) and attitudes concerning urinary incontinence were generally positive $(69.3 \%$, mean $41.6 / 60$, SD 4.5$)$. There was a weak correlation between urinary incontinence knowledge and attitudes $(r=0.175, p=0.001)$. A high level of interest in learning more about urinary incontinence was reported (71.2\%). Conclusions: Hong Kong nursing students had moderate level of knowledge and positive attitude towards urinary incontinence. This study suggests that nursing students in Hong Kong are not well prepared to provide urinary incontinence care. There is still a need to examine the urinary incontinence course content within the nursing programme in Hong Kong.
\end{abstract}

Keywords-Urinary incontinence, knowledge, attitude, nursing students

\section{INTRODUCTION}

Urinary incontinence - a common disorder affects both the physical and psychological well-being of both men and women of all ages [1, 2, 3, 4]. In acute care setting, urinary incontinence is common and always associated with skin injury [4]. A systematic review showed that urinary incontinence is associated with fall risk in community-dwelling older adults [1] Considering sexual health, urinary incontinence reduces overall sexual function, satisfaction, and frequency of sex activity [5, 6]. Psychologically, patients with urinary incontinence may feel embarrassed and anxious, and thus impinging their selfesteem and self-confidence and possibly resulting in depression [7].

Care of patients with urinary incontinence is fundamental in everyday nursing practice. An effective management requires adequate knowledge and positive attitudes about urinary incontinence from nursing professionals. Nursing students who share similar care tasks with qualified nurses should have adequate knowledge to provide quality continence care. There is little evidence to inform the knowledge and attitudes about urinary incontinence among nursing students in Hong Kong. A greater understanding of urinary incontinence concerning knowledge and attitudes among nursing students can help nurse educators identify teaching strategies to prepare nursing students during their clinical learning practice. Therefore, the present study attempted to explore the knowledge and attitude toward urinary incontinence among nursing students in Hong Kong. The findings of this study can provide insights to nurse educators to improve nurse training in urinary care.

\section{METHODS}

\section{A. Design and sampling}

This study was a cross-sectional survey using selfreported questionnaire to collect data. The target population was Hong Kong baccalaureate nursing students. Sample size was estimated based on the total population of five bachelor nursing programmes in Hong Kong, which was 1,820 [8]. A sample of 328 nursing students was required to have $95 \%$ confidence level and 0.05 margin of error. 394 participants were recruited for this study to compensate for a possible $20 \%$ loss of the respondents. Convenience sampling was used to recruit the study participants from nursing students in 5 education institutions in Hong Kong. Inclusion criteria were the nursing students studying year 4 and 5 of their nursing programme. Exclusion criteria were those nursing students who studied psychiatric stream nursing programme, and enrolled nurse conversion nursing programme as they may have different theoretical input and clinical experience related to urinary care.

The study was conducted in February 2017. Data were collected from eligible participants of the five identified institutions. The participants were accessed through social circle of the research team members who collected data from 
participants at campus and hospitals during their academic and clinical study respectively

\section{B. Data collection}

Two sets of validated questionnaires, Urinary Incontinence Knowledge Scale (UIKS) and Urinary Incontinence Attitude Scale (UIAS) were used to address the research objectives. Also, questions were designed to solicit the demographic characteristics and experience in urinary incontinence.

The UIKS was developed by Yuan and William [9]. It comprises 30 statements which measure 6 domains of urinary incontinence knowledge: risk factors, symptoms, impacts, prevention, treatment and management. The responses are rated with 3 options: true, false and don't know. Correct answer was counted as 1 score, and incorrect answer and 'Don't know' were counted as 0 score. Maximum score was 30. Scores more than 24 (>80\%) represented good knowledge, 1824 (60-80\%) indicated moderate knowledge, and lower than 18 $(<60 \%)$ meant poor knowledge. The content validity index of UIKS was 0.75. The internal consistency was 0.72 [10] .

For UIAS, it was developed by Yuan and colleagues [11]. The scale comprises 15 statements which measure attitudes toward urinary incontinence in 4 aspects: lower urinary tract symptoms, prevention, treatment and management. The responses are rated with a 4-point Likert scale (1=strongly disagree, $2=$ disagree, $3=$ agree, $4=$ strongly disagree). The higher the score means the more positive attitude about urinary incontinence. The scale was constructed with seven positive phrases and eight negative phrases to avoid response bias. The internal consistency was 0.65 [10] .

The stability of the UIKS and UIAS was assessed prior to data collection of the present study. The instruments were administered to 30 nursing students in a 2 -week interval. The test-retest reliability coefficient of UIKS ranged from 0.899 to1.00 $(\mathrm{P}=0.01)$ and UIAS was from 0.929-1.00 $(\mathrm{P}=0.01)$, which were acceptable. The internal consistency of the Cronbach's alpha was $0.849(\mathrm{P}=0.01)$ in UIKS and was 0.695 $(\mathrm{P}=0.01)$ in UIAS.

\section{ETHICAL CONSIDERATIONS}

Ethical approval was obtained from the Committee on the Use of Human and Animal Subjects in Teaching and Research (HASC) of Tung Wah College. Implied consent was obtained from the participants. All respondents were voluntary and could withdraw anytime without any consequence or prejudice. No identifying information was presented in the selfadministrated questionnaires. Participants' information was assured with confidentiality and anonymity.

\section{DATA ANALYSIS}

The data was analyzed by IBM SPSS Statistics for Window, version 23.0 (IBM Corp, Armonk, NY). Descriptive statistics and Pearson's correlation coefficient was used to examine the relationships between variables. In all statistical analyses, a $p$-value of less than 0.05 was considered as statistical significant.

\section{RESUlTS}

With 394 questionnaires were administered to respondents, all questionnaires were returned. 392 completed questionnaires were used for data analysis.

\section{A. Demographic data}

Demographic characteristics of all respondents are shown in Table 1. Among the respondents, almost all of them (around 90\%) had experience in taking care of incontinent patients and received training related to urinary incontinence. Around $40 \%$ students had informal experience in taking care of family or friends with urinary incontinence. About 20\% respondents claimed they had experienced urinary incontinence. And around $70 \%$ students were interested in further study of urinary incontinence related information.

\section{B. Knowledge and attitude towards urinary incontinence}

Table II shows the mean scores of both UIKS and UIAS. The overall urinary incontinence knowledge was moderate (76.7\%, mean 22.0/30, SD 4.4) and attitudes concerning urinary incontinence were generally positive $(69.3 \%$, mean 41.6/60, SD 4.5). The mean score of individual domains of the UIKS ranged from 2.8 to 4.5 . The mean score of individual items of the UKAS ranged from 2.9 to 14.5. There was a weak relationship between urinary incontinence knowledge and attitudes $(r=0.175, p=0.001)$.

TABLE I. DEMOGRAPHIC DATA

\begin{tabular}{|c|c|c|}
\hline Variables & Frequency $(\mathbf{N})$ & Percentage (\%) \\
\hline \multicolumn{3}{|l|}{ Age } \\
\hline Mean (SD) & $22.99(0.899)$ & \\
\hline \multicolumn{3}{|l|}{ Year of study } \\
\hline Year 4 & 261 & 66.6 \\
\hline Year 5 & 131 & 33.4 \\
\hline \multicolumn{3}{|l|}{ Institute of studying } \\
\hline Institute A & 53 & 13.5 \\
\hline Institute B & 29 & 7.4 \\
\hline Institute $\mathrm{C}$ & 53 & 13.5 \\
\hline Institute D & 107 & 27.3 \\
\hline Institute $\mathrm{E}$ & 150 & 38.3 \\
\hline \multicolumn{3}{|l|}{ Gender } \\
\hline Male & 140 & 35.7 \\
\hline Female & 252 & 64.3 \\
\hline \multicolumn{3}{|c|}{ Experience of taking care urinary incontinence patient } \\
\hline Yes & 352 & 89.8 \\
\hline No & 40 & 10.2 \\
\hline \multicolumn{3}{|c|}{ Urinary incontinence education and training received } \\
\hline Yes & 363 & 92.6 \\
\hline No & 29 & 7.4 \\
\hline \multicolumn{3}{|c|}{ Experience of taking care of family or friends urinary incontinence } \\
\hline Yes & 163 & 41.6 \\
\hline No & 229 & 58.4 \\
\hline Interest in learning & incontinence & \\
\hline
\end{tabular}




\begin{tabular}{ccc}
\hline Yes & 279 & 71.2 \\
No & 113 & 28.8 \\
\hline
\end{tabular}

TABLE II. MEAN AND STANDARD DEVIATION OF KNOWLEDGE AND ATTITUDE ABOUT URINARY INCONTINENCE

\begin{tabular}{lll}
\hline UIKS & Mean & SD \\
\hline Risk factors & 2.8 & 1.1 \\
Symptom & 4.5 & 1.0 \\
Impact & 4.3 & 1.2 \\
Prevention & 4.0 & 1.3 \\
Treatment & 3.3 & 1.1 \\
Management & 3.0 & 1.0 \\
Overall score & 22.0 & 4.4 \\
& & \\
UIAS & & \\
Lowe urinary tract symptoms & 10.9 & 2.1 \\
Prevention & 2.9 & 0.7 \\
Treatment & 13.3 & 1.7 \\
Management & 14.5 & 2.1 \\
Overall score & 41.6 & 4.5 \\
\hline Note. UIKS=Urinary Incontinence Knowledge Scale, UIAS=Urinary \\
Incontinence Attitude Scale & \multicolumn{2}{|l}{} \\
\hline
\end{tabular}

\section{DISCUSSION}

The purpose of this present study aimed to explore the knowledge and attitude about urinary incontinence among nursing students in Hong Kong. Based on the findings, Hong Kong nursing students achieved a moderate level in urinary incontinence knowledge. It was similar to the study conducted in US where junior and senior nursing students achieved $71 \%$ correct rate [12] but better than the nursing students in China, who achieved $49.9 \%$ correct answers [13]. This result suggests that nursing education in Hong Kong share similar emphasis on urinary continence care with their counterparts in western countries.

When examining the details of the UIKS, the knowledge on risk factor of urinary incontinence was reported as the lowest score among the 6 domains. Further, nearly half of the participants did not have adequate knowledge about the treatment of urinary incontinence. These results showed that participants were not well equipped with adequate knowledge in urinary incontinence even though they had received incontinence education before. Perhaps, nursing students are preoccupied with urinary incontinence care and management which is the core business of their daily practice but ignoring the risk factors of urinary incontinence poses a threat to its prevention [14].

This present study reported that there was significant correlation between knowledge and attitude about urinary incontinence but the relationship is weak. The result is consistent with previous studies $[12,15]$. Hong Kong nursing students had positive attitudes about urinary incontinence. The positive attitude may be due to their eagerness to learn as $71.2 \%$ respondents showed their interests in learning more about urinary incontinence knowledge.

Previous studies revealed that health care professionals with better knowledge of urinary incontinence exhibited a positive attitude towards urinary incontinence care $[16,17]$. In fact, a positive attitude toward urinary care is important to deliver quality care and may lead to a better approach in urinary incontinence care [17].

It is worthwhile to point out that in this present study, around $70 \%$ respondents thought that it was hard to discuss urinary incontinence with patients because it made patients feel embarrassed. Nursing students if holding this attitude will not only undermine continence care but also hinder the development of their clinical reasoning. These findings illuminate nurse educators to explore teaching strategies that not only can promote the mastery of knowledge but also nurture a positive attitude about urinary incontinence.

Similar to most research studies, there are limitations in this present study. This study used a cross-sectional survey which could not assess the change in knowledge and attitude among nursing students. Convenience sampling and uneven distribution of the respondents from different institutes may contribute to selection bias [18].

\section{CONCLUSION}

The present study reports the knowledge and attitude about urinary incontinence among Hong Kong nursing students. These results suggest that nursing students in Hong Kong are not well prepared in continence care. The present study also suggests that knowledge is weakly associated with attitude about urinary incontinence. These findings illuminate nurse educators that it is necessary to employ teaching strategies that could enhance the mastery of urinary continence knowledge and nurture positive attitude in continence care

\section{ACKNOWLEDGMENTS}

The researchers would like to thank the nursing students who participated in this study.

\section{REFERENCES}

[1] Chiarelli, P. E., Mackenzie, L. A., \& Osmotherly, P. G. (2009). Urinary incontinence is associated with an increase in falls: a systematic review. Australian Journal of Physiotherapy, 55(2), 89-95.

[2] Szymanski, K. M., Misseri, R., Whittam, B., Kaefer, M., Rink, R. C., \& Cain, M. P. (2016). Quantity, not frequency, predicts bother with urinary incontinence and its impact on quality of life in adults with spina bifida. The Journal of urology, 195(4), 1263-1269.

[3] Abrams, P., Smith, A. P., \& Cotterill, N. (2015). The impact of urinary incontinence on health-related quality of life (HRQoL) in a real-world population of women aged 45-60 years: results from a survey in $\mathrm{F}$ rance, $\mathrm{G}$ ermany, the UK and the USA. BJU international, 115(1), 143-152.

[4] Junkin, J., \& Selekof, J. L. (2007). Prevalence of incontinence and associated skin injury in the acute care inpatient. Journal of Wound Ostomy \& Continence Nursing, 34(3), 260-269.

[5] Chu, C. M., Arya, L. A., \& Andy, U. U. (2015). Impact of urinary incontinence on female sexual health in women during midlife. Women's Midlife Health, 1(1), 6.

[6] Mota, R. L. (2017). Female urinary incontinence and sexuality. International Brazilian Journal of Urology: Official Journal 
of the Brazilian Society of Urology,43(1), 20-28. http://doi.org/10.1590/S1677-5538.IBJU.2016.0102

[7] Coyne, K. S., Kvasz, M., Ireland, A. M., Milsom, I., Kopp, Z. S., \& Chapple, C. R. (2012). Urinary incontinence and its relationship to mental health and health-related quality of life in men and women in Sweden, the United Kingdom, and the United States. European urology, 61(1), 88-95.

[8] Joint University Programmes Admissions System. (2016). Programmes offered. Joint University Programmes Admissions System. Retrieved October 03, 2016, from: http://www.jupas.edu.hk/en/programmesoffered/by-funding-category/

[9] Yuan, H. B., \& Williams, B. A. (2010). Knowledge of urinary incontinence among Chinese community nurses and community dwelling older people. Health \& social care in the community, 18(1), 82-90.

[10] Park, S., De Gagne, J. C., So, A., \& Palmer, M. H. (2015). Knowledge, attitudes, beliefs, and practices in registered nurses and care aids about urinary incontinence in Korean nursing homes: a cross-sectional survey. Journal of Wound Ostomy \& Continence Nursing, 42(2), 183189.

[11] Yuan, H. B., Williams, B. A., \& Liu, M. (2011). Attitudes toward urinary incontinence among community nurses and community-dwelling older people. Journal of Wound Ostomy \& Continence Nursing, 38(2), 184-189.

[12] Hutchings, J., \& Sutherland, L. (2014). Student nurse understanding of the psychosocial impact of urinary incontinence. Urologic nursing, 34(6), 318-326.

[13] Luo, Y., Parry, M., Huang, Y. J., Wang, X. H., \& He, G. P. (2016). Nursing students' knowledge and attitudes toward urinary incontinence: A cross-sectional survey. Nurse education today, 40, 134-139.

[14] Sumardi, R., Mochtar, C. A., Junizaf, J., Santoso, B. I., Setiati, S., Nuhonni, S. A., ... \& Syahputra, F. A. (2016). Prevalence of urinary incontinence, risk factors and its impact: multivariate analysis from Indonesian nationwide survey. Acta medica Indonesiana, 46(3).

[15] 12Karlowicz, K. A., \& Palmer, K. L. (2006). Engendering student empathy for disabled clients with urinary incontinence through experiential learning. Urologic Nursing, 26(5), 373.

[16] Park, S., De Gagne, J. C., So, A., \& Palmer, M. H. (2015). Knowledge, Attitudes, Beliefs, and Practices in Registered Nurses and Care Aids About Urinary Incontinence in Korean Nursing Homes. Journal of Wound, Ostomy and Continence Nursing, 42(2), 183-189.

[17] Hälleberg Nyman, M., Forsman, H., Ostaszkiewicz, J., Hommel, A., \& Eldh, A. C. (2017). Urinary incontinence and its management in patients aged 65 and older in orthopaedic care-what nursing and rehabilitation staff know and do. Journal of clinical nursing, 26(21-22), 3345-3353.

[18] Polit, D. F., \& Beck, C. T. (2008). Nursing research: Generating and assessing evidence for nursing practice. Lippincott Williams \& Wilkins. 